\title{
$\begin{array}{ll}\text { Research Square } & \text { Preprints are preliminary reports that have not undergone peer review. } \\ \text { They should not be considered conclusive, used to inform clinical practice, }\end{array}$ or referenced by the media as validated information. \\ Twin Deliveries: The Prevalence and Perinatal Outcomes in Public Hospitals in Dar es Salaam City, Tanzania
}

\section{Zavery Benela}

Mbeya Referral Hospital

Alfred Chibwae ( $\square$ achibwae@gmail.com )

CUHAS BUGANDO https://orcid.org/0000-0002-8982-4086

Ola Jahanpour

Kilimanjaro Christian Medical University College

Dismas Matovelo

Catholic University of Health and Allied Sciences

\section{Research article}

Keywords: Twin Pregnancy, Perinatal outcomes, Tanzania

Posted Date: February 21st, 2020

DOI: https://doi.org/10.21203/rs.2.17959/v2

License: (c) (1) This work is licensed under a Creative Commons Attribution 4.0 International License. Read Full License 


\section{Abstract}

Background The perinatal mortality rates are five times higher in twin pregnancies than singleton pregnancies, therefore antenatal management and safe delivery of twin pregnancies are important issues in obstetrics. This study aimed at providing data on the proportion of twin deliveries in four public hospitals in Dar es Salaam and an insight on the fetal outcomes in relation to their modes of delivery. Methods This was a cross sectional study in which all women who delivered twin babies were interviewed and medical records on their delivery summary were obtained in the labour and post-natal wards in four public hospitals in Dar es Salaam between July and December 2011. Post-natal follow up was done on seventh day by contacting women by telephone to establish the neonatal status. Results There were 33,638 total deliveries of which 672 were twin deliveries making the prevalence of 2.0\% (20 per 1,000 births). Of all twin deliveries analyzed (666 pairs), 373(56.0\%) had the diagnosis of twin pregnancy made antenatally. Vaginal delivery was the major mode of delivery $(77.3 \%)$. whereas combined delivery in which the first twin was delivered vaginally and the second twin by caesarian section accounted for only $2.6 \%$. At birth $1252(94 \%)$ of twins were alive, 60(4.5\%), were fresh stillbirths and 20(1.5\%) were macerated stillbirths. Low Apgar score was more to first twins delivered vaginally compared to first twins ( $p$-value=0.003). Low Apgar score $(A S<7)$ was more amongst second twins delivered vaginally at 30 minutes or longer $27(48.2 \%)$ compared to twins delivered in less than 30 minutes $72(15.4 \%)$, ( $p$-value=0.001). Conclusion There was a significant association between vaginal delivery and low Apgar score at one minute. Long duration of twin to twin delivery interval was associated with low Apgar score of the second twins delivered vaginally. Perinatal mortality rate was also higher in the second twins compared to the first twins. The time delivery interval of the second twin should be made as short as possible by active management of all second twins. Neonatal facilities are required in all hospitals conducting twin deliveries to care for premature babies.

\section{Background}

The phenomenon of twinning has fascinated humankind throughout recorded history. Twins have often been regarded as being inherently different from singletons, and societal responses to their birth have ranged from awe to fear [1]. Twin fetuses most commonly result from fertilization of two separate ova and are termed asdouble-ovum, dizygotic or fraternal twins. About a third as often, twins arise from a single fertilized ovum that subsequently divides into two similar structures, each with the potential for developing into a separate individual. These twins are termed as single-ovum, monozygotic, or identical twins (2). All dizygotic twins and onethird of monozygotic twins have separate inner and outer amniotic sacs and are thus dichorionic-diamniotic. Two thirds of monozygotic twins have a single outer amniotic sac and two inner sacs (monochorionic diamniotic) and about $1 \%$ of twins will share their inner sac (monochorionicmonoamniotic) [2].

Twin pregnancies are more prone to complications than singleton pregnancies. Early in pregnancy, there is high risk of miscarriage. Sometimes only one fetus dies and is reabsorbed resulting in 'vanishing twin syndrome' [3]. Other complications associated with twin pregnancy include a high incidence of hypertension (including pregnancy-induced hypertension, pre-eclampsia and eclampsia), gestational 
diabetes mellitus, bleeding in pregnancy (placenta praevia or abruption), preterm birth, small-forgestational-age babies due to intrauterine growth restriction (IUGR), postpartum hemorrhage (PPH), congenital malformations, and twin to twin transfusion syndrome (TTTS)[2, 4].

Twin pregnancies in the general population comprise about $1 \%$ of all pregnancies, but can account for up to $10 \%$ of perinatal mortality[5]. Low birth weight and prematurity are the main causes of high perinatal morbidity and mortality in twins, whereas malpresentation and other hazards of delivery are next in order of concern. For these reasons, a twin delivery is considered high-risk. Mode of delivery remains a subject of a controversy and discussion among obstetricians due to its potential effect on issues such as timing of delivery, malpresentation and risk of PPH[6, 7].

Since perinatal mortality rates are 3-6 times higher in twin pregnancies than singleton pregnancies, antenatal management and safe delivery of twin pregnancies are important issues in obstetrics [8, 9]. The authors have found no comparable focusing on multiple pregnancies and neonatal outcomes by mode of delivery in Tanzania especially in Dar es salaam. Therefore, this study aimed at determining the prevalence, mode of delivery and neonatal outcomes of twin deliveries in four public hospitals in Dar es Salaam.

\section{Methods}

\section{Study area and design}

This observational cross-sectional study was conducted in four public hospitals in Dar es Salaam that provide maternal and child health services from 1st July to 31st December 2011. Thehospitals were Muhimbili National Hospital (MNH), a tertiary and University teaching hospital, and three municipal hospitals: Amana hospital (Ilala Municipality), Mwananyamala hospital (Kinondoni municipality), and Temeke hospital (Temeke municipality).

$\mathrm{MNH}$ had an average of 20 to 30 deliveries per day, including 8 to 12 operative deliveries (elective and emergency). The average number of multiple pregnancies delivered per month was estimated to be 20-30. Temeke hospital had an average of 40-60 deliveries per day,of which 2-4 were caesarian sections. The average number of multiple pregnancies delivered per month was30-40. Mwananyamala hospital had an average of 35-45 deliveries per day with 4-6 caesarian sections. The average number of multiple pregnancies delivered per month was 15-25. Amana hospital had 40-60 deliveries per day of which 3-5 were caesarian sections. The average number of multiple pregnancies delivered per month was 15-20.

All women admitted tolabour wards or post-natal wards who had already delivered were included in our study (along with their infants) from 1st July to 31st December 2011.

\section{Data collection}

A structured closed-question English questionnaire was translated into Swahili and used for data collection. Data was collected by four trained research assistants (Nursing officers), one in each hospital. At $\mathrm{MNH}$, the principal investigator $(\mathrm{PI})$ collected the data when the assistant was absent. Pretesting of the 
questionnaire was done with each assistant to ensure reliability. Data was collected daily from women who had delivered twin babies whilst admitted to a labour ward or post-natal ward. Data was collected after management for the mother and newborns had been completed according to the existing respective hospital protocols. Explanation about the study was provided and informed written consent to participate obtained. Counselling was provided for all women who had experienced either a still birth or an early neonatal death before continuing with the interview.

A summary of information about each delivery was obtained from the patient's medical record or antenatal clinic card, which included the time of delivery, sex, birth weight, and Apgar score of the babies. In the case of caesarean delivery, the indications and whether this was done as an emergency or elective was crosschecked on the hospital records. Gestational age (in weeks) at the time of delivery was estimated either by calculation from the last menstrual period (LMP), or from an early antenatal ultrasound, if done.

The hospital delivery registers were checked daily to ensure all twin deliveries had been identified. The PI also kept track of the neonates, especially those who were admitted in the neonatal unit at $\mathrm{MNH}$, and communicated with research assistants about the referred neonates. The reasons for admission for each neonate were obtained from medical files, as recorded by the attending doctors. Each woman was asked for their cell phone number (or that of a spouse/partner/relative), in order to follow them up seven days after delivery, to obtain information on the condition of the neonates by telephone.

\section{Data analysis}

Data collected was entered into EpiData software and data cleaning was done. Data was analyzed using the Stata version 10. Frequency and distribution tables were created to show the number of twin deliveries as a proportion of the total deliveries in each hospital, and mode of delivery for the first and second twins. The association between neonatal outcome, and the mode of delivery and inter-twin delivery interval for vaginal delivery, were determined using the Chi square test. p-values of less than 0.05 were taken as statistically significant.

\section{Ethical Considerations}

The study was approved by the Research and Publication Committee of Muhimbili University of Health and Allied Sciences (MUHAS). Permissionto conduct the study was obtained from the MNH Director, the Municipal Medical Officers of Health from Temeke, llala and Kinondoni municipalities and from the Medical Officer in Charge of each hospital.

Women meeting the inclusion criteria were provided with an explanation of the aims of the study, its potential benefits and were reassured that there were no risks associated with participating. All information obtained was gained with consent and used only for the present study. Informed written consent was obtained from each participant before starting the interview. Women who had experienced a perinatal death were counselled by the $\mathrm{PI}$ or a research assistant, as all were senior health staff trained in patient counselling. 


\section{Results}

\section{Demographic characteristics of the studied population in the four hospitals}

A majority $507(76.1 \%)$ of the women in this study were aged between $20-34$, with a median age of 28 years and a range of $16-46$ years. Of the women studied, $587(88.1 \%)$ were either married or cohabiting and $11.4 \%$ were single. About a half of the participants had been educated to a secondary school level, accounting for $50.6 \%$ of women. A further $32.7 \%$ had been educated to primary school level. At the time of delivery, $46.7 \%$ of the women studied had an estimated gestational age of less than 37 weeks and the mean gestation age at the time of delivery was $36.2 \pm 3.2$ weeks ( see table 1 ).

\section{Prevalence of twin deliveries in the four hospitals}

There was a total of 33,638 deliveries in the four hospitals during the six-month period (July-December 2011) covered by this study. Of the 33,638 deliveries, 672 (2.0\%) were twin deliveries. Out of the 666 twin deliveries, $373(56.0 \%)$ were identified as twin pregnancies during the antenatal period. In 30 cases (8\%) twins were identified only clinically and in 176 cases (47.2\%) twins were identified only using obstetric ultrasound.The remaining 167 cases (44.8\%) were identified by both methods.

Muhimbili National Hospital had a total of 4813 deliveries with 195 (4.1\%) twin deliveries, Temeke hospital had a total of 10429 deliveries with 228 (2.2\%) twin deliveries, Mwananyamala hospital had a total of 7490 deliveries with $132(1.8 \%)$ twin deliveries and Amana hospital had a total of 10,906 deliveries with 17 (1.1\%) twin deliveries. A total of 666 twin deliveries, resulting in the delivery of 1,332 twin babies, fulfilled the study inclusion criteria. Five pairs had a gestational age of less than 28 weeks and in one pair a gross congenital malformation (anencephaly) was present. Hence were excluded from the study.

\section{Mode of delivery of twins at the four hospitals}

A majority $515(77.3 \%)$ of the twin pregnancies were delivered vaginally, $134(20.1 \%)$ were delivered by caesarian section, whilst $17(2.6 \%)$ had a combined delivery (the first twin was delivered vaginally and the second by caesarian section). Roughly three quarters (76.2\%) of all caesarian sections were done as an emergency as compared to $23.8 \%$ which were done on an elective basis. Muhimbili National Hospital had an almost 1:1 ratio of vaginal delivery to caesarian section births (see table 2).

\section{Neonatal outcome at birth according to the mode of delivery}

At the time of delivery, 1252 of the twins (94\%) were alive, 60 (4.5\%) were fresh stillbirths (FSB) and 20 (1.5\%) were macerated stillbirths (MSB0 as shown in table 3a). Low Apgar scores were more common in first twins delivered vaginally compared to first twins delivered by caesarian section: $76(14.5 \%)$ and 5 (3.5\%), respectively. This difference was statistically significant ( $p$-value=0.003). $116(22.2 \%)$ second twins delivery vaginally had low Apgar scores compared to $11(7.7 \%)$ second twins delivered by caesarian section and this difference was also statistically difference ( $p$-value $=0.001)$. There was no significant difference in fresh stillbirths or macerated stillbirths in first and second twins between the two modes of delivery, as shown in table3b. 


\section{Indications for caesarian section at the four hospitals}

Prolonged or obstructed labour was the most common indication given for caesarian delivery overall $(18.5 \%)$ followed by previous caesarian delivery $(16.9 \%)$. Ten caesarian sections $(5.6 \%)$ were done due a provisional diagnosis of Cephalopelvic disproportion (where the baby's head is too big to fit through their mother's pelvis), but intra-operatively these were identified as undiagnosed twins (see table 4a). At Muhimbili National hospital, previous caesarian delivery accounted for $42.4 \%$ of the elective caesarian sections, with the second most common indication being the first twin presenting as breech (26.9\%). Of the 80 indications for emergency caesarian section, 13 (16.3\%) indications were previous caesarian sections. This would usually be an indication for an elective caesarian section in these circumstances, as shown in table 4b.

\section{Time interval for vaginal delivery of second twins and their outcomes}

Low Apgar scores (AS $<7$ ) were more common amongst second twins delivered vaginally at 30 minutes or longer $(27 ; 48.2 \%)$ compared to twins delivered in less than 30 minutes $(72 ; 15.4 \%)$. This was statistically significant both at one minute and five minutes ( $p$-value $<0.0001)$. There was no significant difference in the rate of stillbirths for second twins delivered vaginally in less than 30 minutes or more than 30 minutes ( $p$ value $=0.44)$. Table 5 summarizes these results.

\section{Perinatal outcomes}

Seven days after delivery, neonates were followed up by contacting either the mother or father, from whom a cell phone number was taken during the initial interview. Of the 1,332 babies delivered, we managed to collect data on day seven for 1,216(91.3\%) babies comprising 606 of the first twins (91.0\%) and 610 of the second twins $(91.6 \%)$. Those lost to follow up were not used in the calculation of the perinatal mortality rate: 60 (9.0\%) first twins and $56(8.4 \%)$ second twins. The overall perinatal mortality of twins in the four hospitals was 155 per 1,000 births. Second twins (184 per 1,000 births) had a higher perinatal mortality compared to the first twins (125 per 1,000 births) table 6. During the study period (July-December 2011) Muhimbili National Hospital had an overall perinatal mortality of 72 per 1000 births (total deliveries 4813 , stillbirths 320 and early neonatal deaths 25 ).

Amongst neonates who were still admitted to neonatal units at seven days, there were a number of different reasons for admission. In total, $89(16.8 \%)$ first twins and $93(18.7 \%)$ second twins were in this group. Whilst in some cases there were multiple reasons for admission, prematurity was the leading cause of admission of both first twins $(51 ; 48.6 \%)$ and second twins $(62 ; 53.4 \%)$, see Table 7.

\section{Discussion}

The birth rate of monozygotic twins is consistent worldwide (approximately 4 per 1000 births). However, birth rates of dizygotic twins vary by race. The highest birth rate of dizygotic twinning occurs in African nations, and the lowest birth rate of dizygotic twinning occurs in Asia[10]. 
The prevalence of twin deliveries in the four public hospitals of Dar es Salaam was 2.0\%, equivalent to 20 per 1,000 births. These findings are comparable to a study done in two rural district hospitals in the South Western Highlands of Tanzania where the prevalence ranged from 15 to 20 per 1,000 births [11]. Both of these studies were based on hospital data. However, the present study provides data on an urban population whose demographic characteristics might differ to the rural population studied previously. The $2.0 \%$ prevalence we observed is lower than a study conducted in Sumve district hospital, Kwimba in Mwanza which had prevalence of 39 per 1000 births [12]. In our study, MNH had a significantly higher rate $(4.1 \%)$ of twin deliveries compared to the municipal hospitals where we collected data. This may be because MNH was likely to receive twin pregnancies from the municipal hospitals, as these are classified as high-risk pregnancies during antenatal care and delivery.

The findings in this study also showed a lower prevalence of twin deliveries compared to those found in Western Africa. A study in Southwest Nigeria recorded an overall average frequency of 40.2 per 1000 deliveries which ranks among the highest recorded rates of twin births in the world [13]. The difference in prevalence of twins between this study and those in West Africa may be due to differences in diet, maternal history of twinning and socio-environmental factors which are said to influence the twinning rate. The rate of twinning also appears to be higher in developed counties (2.7-2.8\%) compared to this study. Several reports attribute this to increased use of Assisted Reproductive Technology (ART) which is not widely available in developing countries[14].

The optimal safe mode of delivery of twins remains a challenge and a subject of controversy among obstetricians. In this study the major mode of delivery was vaginal delivery accounting for $77.3 \%$ of all twin deliveries compared to $20.1 \%$ delivered by caesarian section. The rate of caesarean section in this study is lower compared to other studies [15-18]. A study by Mutihir et al found the rate of caesarian sections to be $41.3 \%$ in Nigeria [19]. Also, in some developed countries [20], the rate of caesarian section in twin delivery has been increasing. Some factors which have correlated with the increase in caesarean section rate include the decline in internal version and breech extraction of a second transverse lie twin [21]. In this study, the presentation of the first and second twins was not studied, which may have influenced the mode of delivery.

Among the caesarian deliveries, $76.2 \%$ were done as emergencies and $23.8 \%$ were planned. The delivery mode in a majority of twin deliveries is decided by the clinician attending the patient during antenatal care, labour and delivery. However, in a few cases, the mode of delivery will be planned during the antenatal period. In this study, about two thirds of all twins delivered had been identified during the antenatal period, and approximately one fifth of them had their mode of delivery planned in the antenatal period. The American College of Obstetricians and Gynecologists (ACOG) suggests that the best route for the twin delivery should be based on the presentation of the fetuses, the ease of fetal heart rate monitoring, and maternal and fetal status [22].

Common indications for caesarian section were prolonged or obstructed labour (16.9\%) and previous caesarian delivery (18.5\%). For those who had combined delivery, retained second twin accounted for $5.6 \%$ of all indications. Other indications for combined delivery were transverse lie and cord prolapse. 
Undiagnosed twins during the antenatal period and during labour were common. This was reflected in the fact that $10(5.6 \%)$ indications for caesarian section were Cephalopelvic disproportion. Intra-operatively, of course, a twin pregnancy was diagnosed. It is important to make the diagnosis of twin pregnancy during the antenatal period in order to plan the mode of delivery.

The modes of delivery at MNH were almost a 1:1 ratio between vaginal and caesarian delivery. This may be explained by the fact that twin pregnancies and deliveries are high-risk with many associated complications, likely to be referred to the tertiary centre. Indeed, in this study $46.7 \%$ of all twin pregnancies delivered at an estimated gestation age of less than 37 weeks (preterm delivery). With a risk of preterm delivery, municipal hospitals tend to refer these women to $\mathrm{MNH}$ for premature neonatal care. Also, in twin pregnancies where there has been a previous caesarian delivery, the mother is likely to attend the antenatal clinic at the tertiary hospital. There is no trial of labour in twin pregnancies with a previous caesarian delivery, accounting for the high rates of caesarian deliveries at MNH compared to the municipal hospitals.

In this study, there were lower Apgar scores at one minute in first twins delivered vaginally compared to first twins delivered by caesarian section. There were also lower Apgar scores at one minute in second twins delivered vaginally compared to second twins delivered by caesarian section. These findings agree with a Korean study by Ji Young at el who found that one-minute Apgar scores of twins delivered vaginally were 2-points lower those delivered by caesarean section $(p=0.048)$. In the same study, five minute Apgar scores were still 1 point lower in the vaginal delivery group than in the cesarean delivery group $(p=0.038)$ [9]. In this study, there was no statistically significant difference in Apgar scores observed at five minutes and no statistically significant difference in the number of stillbirths between the two modes of delivery.

In contrast to this study, a study by Dera et al in Poland showed a significant tendency towards low one minute Apgar score in the second twins delivered vaginally, but when the score was grouped to low $(<7)$ and normal $(\geq 7)$ Apgar score, the final data did not indicate any statistically significant differences between the two modes of delivery[5]. However, the study by Dera et al was a randomized study with either planned vaginal delivery group or planned caesarian section group. This was not the case in the present study in which the mode of delivery in the majority of cases was not pre-planned. This may account for the discrepancy in findings.

In pairs of twins, the second-born twin is more prone to birth asphyxia, which is related to delayed delivery. In this study, fresh stillbirth and low Apgar scores (at one and five minutes) of the second twins delivered vaginally were significantly more common when the inter-twin delivery interval was 30 minutes or longer compared to those delivered in less than 30 minutes ( $p$-value $<0.0001)$. These findings concur with literature that stresses the risk associated with a long duration of delivery of the second twin. Leung et al observed that the risks of fetal distress and acidosis in the second twin are higher when twin-to-twin delivery interval is beyond 30 minutes[23]. Also, a population-based cohort study in Hesse, Germany by Stein et al found that an increasing time interval was related to a decline in the mean umbilical arterial $\mathrm{pH}$, base excess, fetal acidosis and Apgar scores of less than seven at one, five at ten minutes[24]. Schmiz et al recorded an inter-twin delivery interval of 4.9+/-3.2 minutes after vaginal birth of the first twin. With this very short inter-twin delivery time, the perinatal outcomes were not different according to the mode of 
delivery [25]. Adverse outcomes (Apgar score $<7$ and fresh stillbirth) in second twins delivered vaginally in this study possibly reflect inadequate active management of the second twin or lack of proper selection criteria for right mode of delivery before or during labour. Therefore, it is important to shorten the inter-twin delivery interval as this may be the most important factor in the inconsistent prognosis of second twins.

Twin deliveries have a large impact on perinatal mortality rates. The perinatal mortality rate for the second twins (184 per 1000 births) in this study was higher compared to the first twins (125 per 1,000 births) with an overall perinatal mortality rate of 155 per 1000 births. Despite being high, this overall perinatal mortality rate was lower compared to a study by Kidanto et al at MNH which found a perinatal mortality of 269 per 1,000 births for multiple pregnancies (of which the majority were twin pregnancies). The study by Kidanto et al was a retrospective analysis of hospital data over five years which might be more reliable, as in the present study some data was missing [26]. The perinatal mortality rate in this study is high compared to another study in south western Tanzania where the perinatal mortality for twins was 57 per 1000 births. Both of the studies were based on district hospital data [11]. Most prospective studies show low twins perinatal mortality rates. This is probably related to the prior antenatal diagnosis of all twins, careful intrapartum monitoring, planned mode of delivery and inclusion of uncomplicated pregnancies. The poor outcome for second twins (high perinatal mortality rate) in this study may be related to lack of early diagnosis and inadequate intrapartum management of the second twins. On day seven $89(16.8 \%)$ and 93 $(18.7 \%)$ of the first and second twins respectively were admitted in the neonatal units. Prematurity was the leading cause of admission for both first and second twins which reflects the high proportion (46.7\%) of preterm deliveries in this study.

The limitations of this study include missing data on the neonatal status of some of the twins on the seventh day after delivery. This was due to difficulty contacting the participants (including some not having cell phones). This hinders the reliability of the perinatal mortality rates. This study provides data that indicates twin deliveries are common in these four public hospitals but, being a hospital-based study and limited to public hospitals, we cannot generalize these findings to represent the whole population of Dar es Salaam or Tanzania in general.

\section{Conclusions}

Twin deliveries in four public hospitals in Dar es Salaam contribute to about $2.0 \%$ of all deliveries, with $\mathrm{MNH}$ having the highest proportion of twin deliveries. The majority of twin deliveries are delivered vaginally; while for those who delivered by caesarian section, the surgery was largely done on emergency basis. This is likely due to a low proportion of twins being diagnosed antenatally and a low proportion of planned deliveries. However, this study does not come to a conclusion on the best mode of delivery for twin pregnancies.

A long twin-to-twin delivery interval is associated with adverse outcomes of the second twins delivered vaginally. The perinatal mortality rate was also higher in the second twins compared to the first twins. This is likely due to inadequate intrapartum management of the second twins. 
The delivery interval should therefore be made as short as possible by active management of all second twins. Neonatal facilities are required in all hospitals conducting twin deliveries to care for premature babies.

\section{Abbreviations}

AS: Apgar score, ANC: Antenatal Clinic, ART: Assisted Reproductive Technology, CS: Caesarean Section, IPPM: Intramural Private Practice Muhimbili, IUGR: Intrauterine Growth Restriction, LWB: Low Birth Weight, MNH: Muhimbili National Hospital, MUHAS: Muhimbili University of Health and Allied Sciences, NPC: New Paediatrics Complex, PMR: Perinatal Mortality Rate, FSB: Fresh Stillbirth, MSB: Macerated Stillbirth, TTTS: Twin-Twin Transfusion Syndrome, VBAC: Vaginal Birth after Caesarean section, VLBW: Very Low Birth Weight, WHO: World Health Organization

\section{Declarations}

\section{Ethics approval and consent to participate}

The study was approved by the Research and Publication Committee of Muhimbili University of Health and Allied Sciences (MUHAS). Permissionto conduct the study was obtained from the MNH Director, the Municipal Medical Officers of Health from Temeke, llala and Kinondoni municipalities and from the Medical Officer in Charge of each hospital.

Women meeting the inclusion criteria were provided with an explanation of the aims of the study, its potential benefits and were reassured that there were no risks associated with participating. All information obtained was gained with consent and used only for the present study. Informed written consent was obtained from each participant before starting the interview. Women who had experienced a perinatal death were counselled by the $\mathrm{PI}$ or a research assistant, as all were senior health staff trained in patient counselling.

\section{Consent for publication}

Not applicable.

\section{Competing interests}

The authors declare that they have no competing interests.

\section{Funding}

The study had no external funding. All operational costs were met by authors

\section{Availability of data and materials}


The datasets generated and analyzed during the current study are available from the corresponding author on reasonable request.

\section{Acknowledgements}

The authors acknowledge all those who participated in the preparation of this manuscript and those who were involved in the care of our study patients. Special thanks go to women and their twin babies who were involved in this study. Also, we acknowledge the nurses who supported us during data collection.

\section{Authors' contributions}

ZB: Principal investigator, concept development, data collection, data analysis and interpretations; AC: Drafting of the manuscript, OJ and DM: manuscript development. All authors have read and approved the final version of this manuscript, including the authorship.

\section{References}

1. Gabbe, S.G., et al., Obstetrics: Normal and Problem Pregnancies E-Book. 2016: Elsevier Health Sciences.

2. Corsello, G. and E. Piro, The world of twins: an update. J Matern Fetal Neonatal Med, 2010. 23 Suppl 3: p. 59-62.

3. Brick., G., Multiple birth versus single birth issues. The Australian and New Zealand Journal of Obstetrics and Gynecology, 2006. 46 (suppl)(1): p. 529-537.

4. Chan., P.F.Y., Obstetric Implications of multiple gestation. The Australian and New Zealand Journal of Obstetrics and Gynecology, 2006. 46(suppl.)(1): p. 11-13.

5. Anna Dera, G.H.B., Louis Keith, The mode of delivery in twin pregnancy Part I. Neonatal outcome. Archives of Perinatal Medicine 2008. 14(1): p. 7-22.

6. Hack, K., et al., Perinatal mortality and mode of delivery in monochorionic diamniotic twin pregnancies $\geq 32$ weeks of gestation: a multicentre retrospective cohort study. BJOG: An International Journal of Obstetrics \& Gynaecology, 2011. 118(9): p. 1090-1097.

7. Antsaklis, A., F.M. Malamas, and M. Sindos, Trends in twin pregnancies and mode of delivery during the last 30 years: inconsistency between guidelines and clinical practice. Journal of perinatal medicine, 2013. 41(4): p. 355-364.

8. Minakami, H. and I. Sato, Reestimating date of delivery in multifetal pregnancies. JAMA, 1996. 275(18): p. 1432-4.

9. Kwon, J.Y., et al., Umbilical arterial blood gas and perinatal outcome in the second twin according to the planned mode of delivery. Int J Med Sci, 2011. 8(8): p. 643-8.

10. Fletcher GE, Z.T., Pramanik AR, Ford SP., Multiple Births, Accessed through http://emedicine.medscape.com/article/977234-overview. 
11. van Roosmalen, J., Multiple pregnancy as a risk factor in rural Tanzania. Trop Geogr Med, 1988. 40(3): p. $196-200$.

12. Walraven, G.E., et al., Comparison of perinatal outcome in rural Tanzania as obtained from a prospective community-based survey and hospital data. Trop Geogr Med, 1994. 46(1): p. 11-3.

13. Akinboro, A., M.A. Azeez, and A.A. Bakare, Frequency of twinning in southwest Nigeria. Indian J Hum Genet, 2008. 14(2): p. 41-7.

14. WHO, Neonatal and perinatal mortality : country, regional and global estimates. 2006.

15. Muganyizi, P., et al., Caesarean section: trend and associated factors in Tanzania. African Journal of Midwifery and Women's Health, 2008. 2(2): p. 65-68.

16. Eleje, G., et al., The rate of Caesarean section in Nnewi, Nigeria: A 10-year Review. Afrimedic Journal, 2010. 1(1): p. 11-14.

17. Lyimo, F.M., et al., Single dose of gentamicin in combination with metronidazole versus multiple doses for prevention of post-caesarean infection at Bugando Medical Centre in Mwanza, Tanzania: a randomized, equivalence, controlled trial. BMC pregnancy and childbirth, 2013. 13(1): p. 123.

18. Mutihir, J.T., P.H. Daru, and I.A. Ujah, Elective caesarean sections at the Jos University Teaching Hospital. Tropical Journal of Obstetrics and Gynaecology, 2005. 22(1): p. 39-41.

19. Mutihir, J.T. and V.C. Pam, Obstetric outcome of twin pregnancies in Jos, Nigeria. Niger J Clin Pract, 2007. 10(1): p. 15-8.

20. Wanyonyi, S., E. Sequeira, and T. Obura, Caesarian section rates and perinatal outcome at the Aga Khan University Hospital, Nairobi. East African medical journal, 2006. 83(12): p. 651-658.

21. Melchor J.C, B.G., Ruiz R. Corcostegui B, Aranguren G, , Mode of delivery of twins. An 11 years review (1980-1990) Journal of Obstetrics and Gynecology 1992. 12(4): p. 219-222.

22. ACOG Practice Bulletin \#56: Multiple gestation: complicated twin, triplet, and high-order multifetal pregnancy. Obstet Gynecol, 2004. 104(4): p. 869-83.

23. Leung T.-Y., T.W.-H., Leung T.-N. et al. , Effect of twin to-twin delivery interval on umbilical cord blood gas in the second twins. BJOG: Intern. J. of Obstet. and Gynecol. , 2002. 108: p. 63-67.

24. Stein, W., B. Misselwitz, and S. Schmidt, Twin-to-twin delivery time interval: influencing factors and effect on short-term outcome of the second twin. Acta Obstet Gynecol Scand, 2008. 87(3): p. 346-53.

25. Schmitz, T., et al., Neonatal outcomes of twin pregnancy according to the planned mode of delivery. Obstet Gynecol, 2008. 111(3): p. 695-703.

26. Kidanto, H.L., et al., Analysis of perinatal mortality at a teaching hospital in Dar es Salaam, Tanzania, 1999-2003. Afr J Reprod Health, 2006. 10(2): p. 72-80.

\section{Tables}


Table.1; Demographic characteristics of the studied women by hospitals.

\begin{tabular}{llllll}
\hline Maternal & & & Hospitals. & \\
characteristics. & MNH & Temeke & M/mala & Amana & Total \\
& N=195(\%) & N=227(\%) & N=129(\%) & N=115(\%) & N=666(\%) \\
& & & & & \\
\hline Age in years & & & & & \\
$<20$ & $21(10.8)$ & $25(11.0)$ & $13(10.1)$ & $9(7.8)$ & $68(10.2)$ \\
20-34 & $137(70.3)$ & $178(78.4)$ & $99(76.7)$ & $93(80.90$ & $507(76.1)$ \\
$\geq 35$ & $37(18.9)$ & $24(10.6)$ & $17(13.2)$ & $13(11.3)$ & $91(13.7)$ \\
Education level & & & & & \\
No formal & $26(13.3)$ & $6(2.6)$ & $23(17.8)$ & $18(15.7)$ & $73(10.9)$ \\
Primary & $65(33.3)$ & $78(34.4)$ & $41(31.8)$ & $34(29.6)$ & $218(32.7)$ \\
Secondary & $90(46.2)$ & $130(57.3)$ & $55(42.6)$ & $62(53.9)$ & $337(50.6)$ \\
College & $14(7.20$ & $13(5.7)$ & $10(7.8)$ & $1(0.8)$ & $38(5.7)$ \\
Marital status & & & & & \\
Single & $22(11.3)$ & $24(10.6)$ & $20(15.5)$ & $10(8.7)$ & $76(11.4)$ \\
Married/cohabiting & $173(88.7)$ & $201(88.6)$ & $108(83.7)$ & $105(91.3)$ & $587(88.1)$ \\
Divorced & 0 & $2(0.9)$ & $1(0.8)$ & 0 & $3(0.5)$ \\
Parity & & & & \\
1 & & & & \\
2 & $44(22.6)$ & $43(18.9)$ & $31(24.0)$ & $21(18.3)$ & $139(20.9)$ \\
3 & $55(28.2)$ & $61(26.9)$ & $39(30.2)$ & $30(26.1)$ & $185(27.8)$ \\
$\geq 4$ & $48(24.6)$ & $60(15.4)$ & $30(23.3)$ & $32(27.8)$ & $170(25.5)$ \\
Gestation age in weeks & $48(24.6)$ & $63(27.8)$ & $29(22.5)$ & $32(27.8)$ & $172(25.8)$ \\
28- 37 & $89(45.6)$ & $107(47.1)$ & $57(44.2)$ & $58(50.4)$ & $311(46.7)$ \\
$\geq 37$ & $106(54.4)$ & $120(52.9)$ & $72(55.8)$ & $57(49.6)$ & $355(53.3)$ \\
\hline
\end{tabular}

Table 2; Mode of delivery of twins at the four hospitals 


\begin{tabular}{|c|c|c|c|c|c|}
\hline \multirow[t]{2}{*}{ Characteristics } & \multicolumn{5}{|c|}{ Hospitals } \\
\hline & MNH & Temeke & $\mathrm{M} / \mathrm{mala}$ & Amana & Total \\
\hline \multicolumn{6}{|c|}{ Mode of delivery } \\
\hline & $\mathrm{N}=195(\%)$ & $\mathrm{N}=227(\%)$ & $\mathrm{N}=129(\%)$ & $\mathrm{N}=115(\%)$ & $\mathrm{N}=666(\%)$ \\
\hline VD & $94(48.2)$ & $210(92.5)$ & $107(82.9)$ & $104(90.5)$ & $515(77.3)$ \\
\hline CS & $98(50.3)$ & $9(4.0)$ & $18(14.0)$ & $9(7.8)$ & $134(20.1)$ \\
\hline Combined & $3(1.5)$ & $8(3.5)$ & $4(3.1)$ & $2(1.7)$ & $17(2.6)$ \\
\hline \multicolumn{6}{|c|}{ Type of caesarian section } \\
\hline & $\mathrm{N}=101(\%)$ & $\mathrm{N}=17(\%)$ & $\mathrm{N}=22(\%)$ & $\mathrm{N}=11(\%)$ & $\mathrm{N}=151(\%)$ \\
\hline Elective & $26(25.7)$ & $5(29.4)$ & $4(18.2)$ & $1(9.1)$ & $36(23.8)$ \\
\hline Emergency & $75(74.3)$ & $12(70.6)$ & $18(81.8)$ & $10(90.9)$ & $115(76.2)$ \\
\hline
\end{tabular}

VD-Vaginal delivery CS- Caesarian section

Table 3a; Neonatal outcomes at birth in relation to the mode of delivery

\begin{tabular}{llllll}
\hline Outcomes & Vaginal delivery & \multicolumn{2}{l}{ Caesarian section } & Total \\
\hline & Twins 1 & Twins 2 & Twins 1 & Twins 2 & \\
& $\mathbf{N = 5 2 4 ( \% )}$ & $\mathbf{N = 5 2 3 ( \% )}$ & $\mathbf{N = 1 4 2 ( \% )}$ & $\mathbf{N = 1 4 3 ( \% )}$ & $\mathbf{N = 1 3 3 2 ( \% )}$ \\
\cline { 2 - 6 } & & & & & \\
Alive & $498(95.1)$ & $486(93.0)$ & 133(97.7) & 135(94.4) & $1252(94.0)$ \\
FSB & $18(3.4)$ & $27(5.1)$ & $8(5.6)$ & $7(4.9)$ & $60(4.5)$ \\
MSB & $8(1.5)$ & $10(1.9)$ & $1(0.7)$ & $1(0.7)$ & $20(1.5)$ \\
\hline
\end{tabular}

FSB-Fresh stillbirth MSB-Macerated stillbirth

Table 3b; Neonatal outcomes according to the modes of delivery 


\begin{tabular}{|c|c|c|c|c|c|c|}
\hline \multirow[t]{2}{*}{ APGAR score } & VD & CS & \multicolumn{2}{|c|}{ p-value VD } & CS & p-value \\
\hline & $\mathrm{N}=524(\%)$ & $\mathrm{N}=142(\%)$ & & $\mathrm{N}=523(\%)$ & \multicolumn{2}{|l|}{$\mathrm{N}=143(\%)$} \\
\hline MSB & $8(1.5)$ & $1(0.7)$ & & $10(1.9)$ & $1(0.7)$ & \\
\hline FSB & $18(3.4)$ & $8(5.7)$ & 0.20 & $27(5.2)$ & $7(4.9)$ & 0.48 \\
\hline AS $<7$ at $1 \mathrm{~min}$ & $76(14.5)$ & $5(3.5)$ & & $116(22.2)$ & $11(7.7)$ & \\
\hline $\mathrm{AS} \geq 7$ at $1 \mathrm{~min}$ & $422(80.5)$ & $128(90.1)$ & 0.003 & $370(70.7)$ & $124(86.7)$ & 0.001 \\
\hline AS $<7$ at $5 \mathrm{~min}$ & $27(5.2)$ & $1(0.7)$ & & $41(7.8)$ & $6(4.2)$ & \\
\hline $\mathrm{AS} \geq 7$ at $5 \mathrm{~min}$ & $471(89.9)$ & 132(93.0) & 0.099 & $445(85.1)$ & $129(90.2)$ & 0.135 \\
\hline
\end{tabular}

Key; AS- APGAR score, FSB-Fresh stillbirth, MSB-Macerated stillbirths

Table 4a; Indications of caesarian section for the four hospitals

\begin{tabular}{lll}
\hline Indication & Frequency N=178* & Percentage \\
\hline Prolonged/obstructed labour & 33 & 18.5 \\
Previous caesarian section & 30 & 16.9 \\
First twin breech presentation & 17 & 9.6 \\
Twin pregnancy & 16 & 9.0 \\
Malpresentation & 12 & 6.7 \\
Severe pre-eclampsia/eclampsia & 15 & 8.4 \\
Fetal distress & 10 & 5.6 \\
Retained second twin & 10 & 5.6 \\
Bad obstetric history with twin pregnancy & 4 & 2.2 \\
Premature rupture of membranes & 7 & 3.9 \\
Cord prolapsed & 7 & 3.9 \\
CPD with big baby(undiagnosed twins) & 10 & 5.6 \\
Transverse lie & 3 & 1.7 \\
Footling in twin pregnancy & 2 & 1.1 \\
Locked twins & 1 & 0.5 \\
Arm prolapse & 1 & 0.5 \\
\hline
\end{tabular}


* There is more than one indication for caesarian section.

Table 4b; Indications of caesarian section for Muhimbili National Hospital

\begin{tabular}{lll}
\hline Indications & \multicolumn{3}{l}{ Type of caesarian section } \\
& Elective & Emergency \\
& $\mathrm{N}=26(\%)$ & $* \mathrm{~N}=80(\%)$ \\
\hline Prolonged/obstructed labour & 0 & $16(20.0)$ \\
Previous caesarian section & $11(42.4)$ & $13(16.3)$ \\
First twin breech presentation & $7(26.9)$ & $5(6.3)$ \\
Twin pregnancy & $1(3.8)$ & $5(6.3)$ \\
Malpresentation & $2(7.7)$ & $7(8.8)$ \\
Severe pre-eclampsia/eclampsia & $1(3.8)$ & $6(7.5)$ \\
Fetal distress & 0 & $8(10.0)$ \\
Retained second twin & 0 & $2(2.5)$ \\
Bad obstetric history with twin pregnancy & $2(7.7)$ & 0 \\
Premature rupture of membranes & 0 & $5(6.3)$ \\
Cord prolapse & 0 & $5(6.3)$ \\
CPD with big baby(undiagnosed twins) & 0 & $5(6.3)$ \\
Transverse lie & $2(7.7)$ & 0 \\
Footling in twin pregnancy & 0 & $1(1.3)$ \\
Locked twins & 0 & $1(1.3)$ \\
Arm prolapse & 0 & $1(1.3)$ \\
\hline
\end{tabular}

* There is more than one indication for caesarian section.

Table 5; Neonatal outcomes of second twins in relation to inter twin vaginal delivery tim interval. 


\begin{tabular}{llll}
\hline Outcomes & \multicolumn{3}{l}{ Time interval in minutes p-value } \\
& $<30$ & $\geq 30$ & \\
& $\mathbf{N}=467(\%)$ & $\mathbf{N}=56(\%)$ & \\
\cline { 2 - 4 } MSB & $6(1.3)$ & $4(7.1)$ & \\
FSB & $19(4.1)$ & $8(14.3)$ & 0.44 \\
AS $<7$ at 1 min $72(15.4)$ & $27(48.2)$ & \\
AS $\geq 7$ at 1 min 370(79.2) & $17(30.4)$ & $<0.0001$ \\
AS $<7$ at $5 \min 39(8.4)$ & $24(42.9)$ & \\
AS $\geq 7$ at $5 \min 403(86.3)$ & $20(35.7)$ & $<0.0001$ \\
\hline
\end{tabular}

Key; AS-APGAR score, MSB-Macerated stillbirth FSB-Fresh stillbirth

Table 6: Perinatal outcomes and perinatal mortality rate

\begin{tabular}{|c|c|c|c|}
\hline Outcomes & $\begin{array}{l}\text { Twin } \\
{ }^{*} \mathrm{~N}=\end{array}$ & $\begin{array}{l}\text { Twir } \\
* \mathrm{~N}=\end{array}$ & $\begin{array}{l}\text { Total } \\
* N=1216\end{array}$ \\
\hline Stillbirth & 35 & 45 & 80 \\
\hline Early neonatal death & 41 & 67 & 108 \\
\hline Alive and well & 449 & 405 & 846 \\
\hline Alive admitted neonatal units & 89 & 93 & 182 \\
\hline Perinatal mortality per 1000 & 125 & 184 & 155 \\
\hline
\end{tabular}

*Information of 60 first twins and 56 second twins about the neonatal status on day seven wa missing.

Table 7; Causes of twins neonatal admissions by day seven.

\begin{tabular}{|c|c|c|c|c|}
\hline \multirow[t]{2}{*}{ Reasons } & \multicolumn{4}{|c|}{ Twin 1 Percentage Twin 2 Percentage } \\
\hline & \multicolumn{2}{|c|}{$\mathrm{N}=105^{*}$} & \multicolumn{2}{|c|}{$\mathrm{N}=116^{*}$} \\
\hline Prematurity & 51 & 48.6 & 62 & 53.4 \\
\hline Birth asphyxia & 19 & 18.1 & 16 & 13.8 \\
\hline $\mathrm{RDS}$ & 16 & 15.2 & 23 & 19.8 \\
\hline Neonatal jaundice & 7 & 13.7 & 3 & 2.6 \\
\hline Neonatal sepsis & 4 & 3.8 & 8 & 6.9 \\
\hline Pneumonia & 7 & 6.7 & 4 & 3.4 \\
\hline Fracture of the humerus & & 0.9 & 0 & \\
\hline
\end{tabular}


Key; ${ }^{*}$ More than one reason for admission occurred in some neonates, RDS-Respiratory distress syndrome. 